\title{
A PARTICIPAÇÃO DO EGRESSO DA POLI/UPE NA INSERÇÃO NO MUNDO DE TRABALHO: UM COMPARATIVO ENTRE OS EGRESSOS QUE CONCLUIRAM ENSINO MÉDIO NA REDE PÚBLICA E PRIVADA
}

DOI: 10.37702/2175-957X.COBENGE.2021.3506

Arthur Wanderley Ferreira Dos Santos - Arthur.aw109@gmail.com

Escola Politécnica da Universidade de Pernambuco

Rua Poeta Zezito Neves 71

51020-200 - Recife - PE

JOSÉ ROBERTO DE SOUZA CAVALCANTI - JRCAVALCANTI@POLI.BR

UNIVERSIDADE DE PERNAMBUCO UPE

RUA BENFICA 455

50720-001 - RECIFE - PE

Amanda Pereira Sales Cavalcanti - amandasalesc@gmail.com

Escola Politécnica da Universidade de Pernambuco

Rua Manuel de Souza Lopes 63

53020-290 - Olinda - PE

LAURA SILVA SOARES DE MELO - laura.ssmelo@upe.br

Escola Politécnica da Universidade de Pernambuco

Rua Pajeú 456

50800-340 - Recife - PE

Resumo: $O$ presente artigo analisa a participação do egresso da Escola Politécnica de Pernambuco (POLI/UPE) como fator determinante para inserção no mundo de trabalho a partir das atividades que eles desenvolveram durante a graduação, comparando entre dois diferentes perfis de ingresso, os oriundos da Rede de Ensino pública e privada. Foi utilizado um questionário online disponibilizado para preenchimento dos egressos dos 7 cursos de engenharia ofertados pela instituição, formados entre os períodos de 2015.2 e 2019.2, resultando um total de 902 egressos e 217 respostas, sendo estas analisadas por distribuição de frequência. $A$ maioria dos egressos estão atuando na área de engenharia (58,06\%), e a maioria dos que oriundos da rede de pública que estão nesta área possuem curso técnico 
(61,29\%), enquanto os da rede privada, independe da área, não possuem formação prévia (75,33\%). A quantidade de pós-graduados que estão atuando na área de engenharia é maior em relação à outras áreas $(26,62 \%$ e $17,46 \%$ comparado a $4,55 \%$ e $7,94 \%$ dos oriundos da rede privada e pública, respectivamente). Estágios não-obrigatórios mostram-se como diferencial para inserção no mundo do trabalho, principalmente considerando os que exerceram pelo menos 12 meses $(37,01 \%$ e 30,16\% da área de engenharia comparados a $5,2 \%$ e 9,52\% de outras áreas, para rede privada e pública respectivamente). Há também uma notória participação em eventos científicos e iniciação científica durante a graduação. Com isso, a pesquisa conseguiu identificar que a participação ativa dos alunos durante o processo de formação pode ser um diferencial para inserção no mundo de trabalho.

Palavras-chave: Influência na formação. Rede de Ensino de origem. Perfil profissional. Avaliação quantitativa. 


\section{A PARTICIPAÇÃO DO EGRESSO DA POLI/UPE NA INSERÇÃO NO MUNDO DE TRABALHO: UM COMPARATIVO ENTRE OS EGRESSOS QUE CONCLUIRAM ENSINO MÉDIO NA REDE PÚBLICA E PRIVADA}

\section{INTRODUÇÃO}

A Indústria 4.0 tem transformado os sistemas produtivos por meio da automação e digitalização de processos, produtos e modelos de negócios, difundido o uso de tecnologias por diversos âmbitos da sociedade. Essas transformações societárias têm demandado a qualificação de profissionais nas diversas áreas do conhecimento para atender aos anseios da economia digital, criando, assim, novos desafios para a educação brasileira, especialmente, no âmbito da formação profissional (SILVA \& OLAVE, 2020).

Os perfis profissionais sofrem transformações decorrentes da necessidade de readaptação às exigências do mercado de trabalho, onde as organizações tendem a mudar seu cenário e passam a exigir trabalhadores diferenciados com conhecimentos e habilidades. Os profissionais destas organizações necessitam de autonomia sobre os meios e responsabilidade sobre os fins (ROSA JUNIOR, 2017).

Empregabilidade pode ser entendida como a capacidade de um indivíduo se manter no mercado de trabalho, ondem ele se mostra capaz de competir com outros indivíduos por um emprego (VAZ, 2019). Para Carvalho (2011), a conclusão de um curso superior não é o bastante para garantir a conquista de um emprego. Para ele, as empresas passam a requerer dos profissionais qualidades, aptidões e conhecimentos para buscar novas alternativas organizacionais, bem como solucionar seus problemas.

No contexto de crescimento no número de Instituições de Ensino Superior (IES), que se deu a partir de 1996 com o advento da Lei de Diretrizes e Bases da Educação Nacional no 9.394, de 20 de Dezembro de 1996, que flexibilizou a criação de novas IES e de novos cursos de graduação, surge outra preocupação com respeito ou mundo do trabalho: a questão do subemprego. Segundo Tomlinson (2008), graduados estão cada vez mais inserindo-se em áreas do mercado de trabalho que antes eram ocupadas por não graduados, levando a um potencial descompasso entre o nível de qualificação e sua utilidade no mercado. Para Fragoso, Valadas e Paulos (2020), os fatores estruturais, como classe social, gênero e minoria cultural, podem funcionar como forma de reduzir a mobilidade social.

Neste contexto e como forma de manutenção da qualidade dos engenheiros formados, a implementação das Diretrizes Curriculares Nacionais do Curso de Graduação em Engenharia (Resolução CNE/CES no 2, de 24 de abril de 2019), têm-se destacado na busca pela formação cada vez mais voltada para as competências esperadas do egresso e os pontos que o curso de graduação em engenharia deve compreender. Essas diretrizes impactam diretamente no Projetos Pedagógicos de Curso (PPC) e surgem como forma de garantir que os egressos tenham as competências e habilidades mínimas para ingressar no mundo do trabalho.

Em meio a este contexto, surge a preocupação de que o crescimento quantitativo esteja associado à contribuição dessas instituições e cursos à sociedade. Esta preocupação desemboca em pesquisas sobre os efeitos dos cursos ministrados sobre os seus estudantes e, também, sobre os seus egressos (LUIZ, COSTA \& COSTA, 2010). Com isso, é importante avançar na discussão sobre como as IES estão implementando, do ponto de vista da qualidade, a dimensão da prática dos cursos que oferecem à sociedade, para garantir uma sólida relação entre teorias aprendidas e práticas organizacionais que serão vivenciadas pelos profissionais nas suas respectivas áreas (BISSARO, 2015). 
A formação superior deveria promover a procura por melhores empregos, aumentar o crescimento econômico e estimular a empregabilidade (MAYHEW \& KEEP, 1999). No âmbito de inserir o egresso no mundo do trabalho, Guerra e Herrera (2011) mostram como o egresso é o vínculo da universidade com a sociedade e o mercado de trabalho, e para eles, é necessário que se interprete a realidade e necessidades dos graduados para atender as necessidades de crescimento, seja pessoal, profissional e empresarial.

No contexto da Engenharia, a Escola Politécnica de Pernambuco (POLI/UPE) vem se destacando ao longo dos anos por seu pioneirismo na região Nordeste do país no que se refere a promover o fortalecimento do ensino, pesquisa e extensão universitária. A POLI busca constante valorização e atualização de conhecimentos do seu corpo de servidores, professores, técnicos administrativos e, em especial, na formação de futuros profissionais. Este artigo faz referência ao projeto de pesquisa de educação em engenharia, realizada anualmente desde 2016, de avaliação sob a ótica do egresso dos cursos de engenharia da POLI com objetivo avaliar a inserção de seus egressos no mundo do trabalho.

\section{METODOLOGIA}

A pesquisa se caracteriza como do tipo quantitativa, pois recorre à linguagem matemática para descrever as causas de um fenômeno, as relações entre variáveis (FONSECA, 2002), e de objetivo exploratório, porque busca proporcionar maior familiaridade com o problema, com vistas a torná-lo mais explícito ou a construir hipóteses (GIL, 2002). Como instrumento de coleta de dados foi utilizado questionário aplicado online, pois o uso de tecnologias permite um contato mais rápido e preciso com a população de interesse da pesquisa (GIL, CAMELO \& LAUS, 2013).

Foram selecionados para colaborar com a pesquisa, todos os graduados entre os períodos de 2015.2 e 2019.2, dos 7 cursos de engenharia ofertados pela Escola Politécnica de Pernambuco (POLI), a saber: Civil, Computação, Controle e automação, Eletrônica, Eletrotécnica, Mecânica e Telecomunicações, além de mecatrônica que não é mais ofertado. Isso resultou em um total de 902 egressos, sendo os dados disponibilizados pela coordenação da POLI. O questionário esteve disponível na plataforma digital GoogleForms, no período de outubro a dezembro de 2020. Os dados obtidos foram tratados usando o Microsoft Office Excel, e a análise se deu por meio de distribuição de frequências, que segundo Feijoo (2010), é possível sintetizar e organizar os dados coletados de forma clara e significativa, facilitando sua compreensão e evidenciando as tendências significativas desses dados.

O contato com os egressos se deu a partir de redes sociais, e-mails e pelo aplicativo WhatsApp. Vale ressaltar que, segundo Silveira (2009), encontram-se dificuldades no processo de captação de respostas, como bancos de dados desatualizados, dificultando a localização dos egressos, e a disposição dos ex-alunos para cooperar com a pesquisa. Dos 902 egressos selecionados, 217 responderam à pesquisa $(24,06 \%)$, sendo esta amostra válida, considerando uma margem de erro $4,88 \%$ e um nível de confiabilidade de $90 \%$. A Tabela 1 mostra a distribuição dos egressos por curso e o percentual de respostas de cada curso. 
28 a 30 de SETEMBRO

Tabela 1 - Número de resposta dos egressos por curso

\begin{tabular}{c|c|c|c} 
Curso & Total de Egressos & Total de Respostas & Percentual de Retorno \\
\hline Civil & 409 & 100 & $24,45 \%$ \\
\hline Computação & 71 & 12 & $16,90 \%$ \\
\hline Controle e Automação & 14 & 3 & $21,43 \%$ \\
\hline Eletrotécnica & 161 & 42 & $26,09 \%$ \\
\hline Eletrônica & 55 & 11 & $20,00 \%$ \\
\hline Telecomunicações & 46 & 11 & $23,91 \%$ \\
\hline Mecânica & 100 & 26 & $26,00 \%$ \\
\hline Mecatrônica & 46 & 12 & $26,09 \%$ \\
\hline Total & 902 & 217 & $24,06 \%$ \\
\hline
\end{tabular}

Fonte: Os autores (2021).

Para definição dos dados a serem abordados na pesquisa, foi feito uma revisão bibliográfica acerca dos estudos dos egressos no Brasil. A partir dessa pesquisa, foram estabelecidos 4 pontos de abordagem no questionário: dados sociais, que busca a identificação dos perfis sociais dos egressos; dados acadêmicos, que são referentes ao processo de formação e as atividades exercidas antes de concluir a graduação; dados profissionais, relacionados à inserção do formando no mundo de trabalho; dados institucionais, que buscam avaliar os cursos e suas estruturas, utilizando como referência principal o Exame Nacional de Desempenho dos Estudantes (ENADE, 2006).

Foram selecionados cinco tópicos para análise da inserção do recém-engenheiro no mundo de trabalho: Situação de emprego, Área de atuação, Maior nível de formação atual, Tempo que exerceu estágio além do obrigatório e Atividades exercidas durante a graduação. Esses dados foram analisados por natureza da Rede de Ensino que os egressos concluíram o ensino médio (pública ou privada), de modo a entender como essa variável repercute na inserção deles no mundo do trabalho.

\section{RESULTADOS E DISCUSSÕES}

\subsection{Visão geral dos egressos}

A Tabela 2 mostra como estão divididos os egressos em relação a situação de emprego (trabalha ou não trabalha) e a natureza da Rede de Ensino que o egresso concluiu o Ensino médio (privada ou pública). Vale ressaltar que a partir desse ponto, para os egressos que concluíram Ensino médio Rede de Ensino privada será utilizado rede privada, e rede pública para os oriundos da Rede de Ensino pública. É possível observar que a maioria dos graduados, cerca de $83 \%$, estão inseridos no mundo de trabalho. Além disso, no âmbito da Rede de Ensino, é perceptível que os egressos oriundos da rede privada é um pouco mais que o dobro dos egressos da rede pública, 70,97\% em comparação aos $29,03 \%$ respectivamente.

Tabela 2 - Situação de emprego e Rede de Ensino de origem dos egressos

\begin{tabular}{|c|c|c|c|}
\hline Categoria & Situação & Total & Percentual \\
\hline \multirow{2}{*}{ Situação de emprego } & Trabalha & 179 & $82,49 \%$ \\
\hline & Não Trabalha & 38 & $17,51 \%$ \\
\hline \multirow{2}{*}{$\begin{array}{l}\text { Rede de Ensino que o egresso concluiu } \\
\text { Ensino médio }\end{array}$} & Privada & 154 & $70,97 \%$ \\
\hline & Pública & 63 & $29,03 \%$ \\
\hline
\end{tabular}

Fonte: Os autores (2021). 
O Gráfico 1 mostra a distribuição dos egressos entre 7 principais áreas identificadas nas respostas. É possível notar que mais da metade dos egressos $(58,06 \%)$ estão inseridos na área de engenharia, seguidos pela área administrativa $(7,37 \%)$.

Gráfico 1 - Distribuição dos egressos por área de atuação

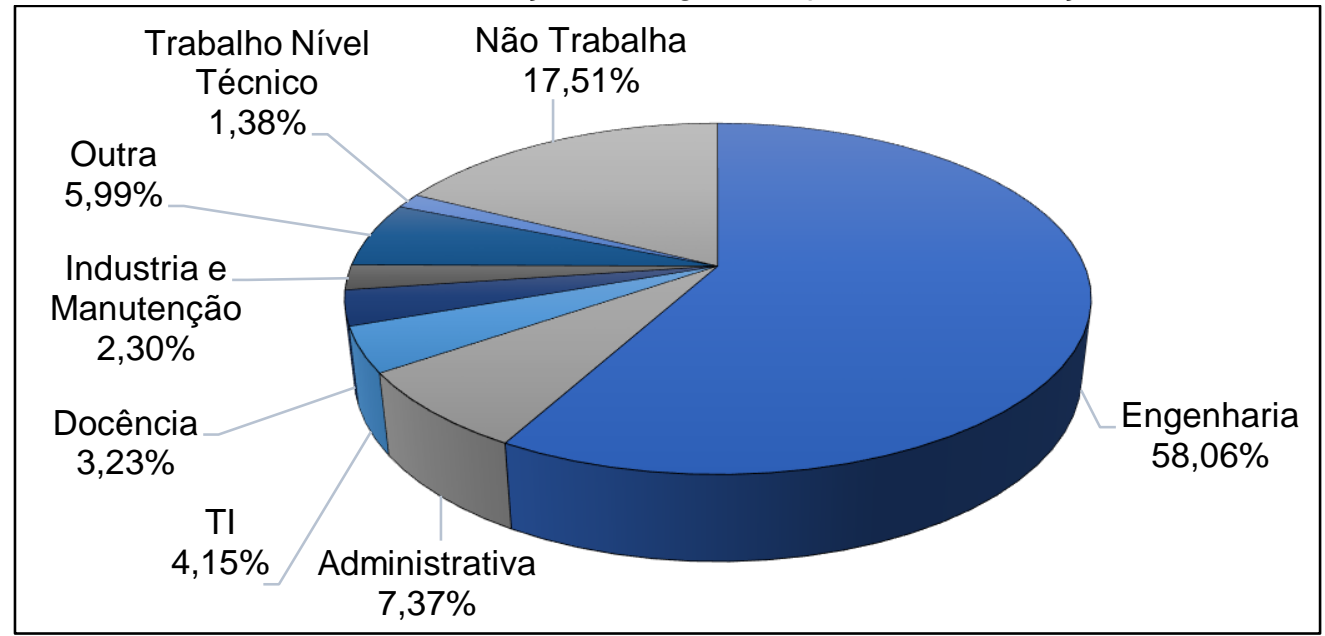

Fonte: Os autores (2021).

Já o Gráfico 2 mostra como estão distribuídos os egressos oriundos de cada Rede de Ensino entre as áreas de atuação. As áreas foram compiladas em 3: engenharia, egressos que estão atuando na área de engenharia; outras áreas, os que estão empregados, mas não atuam na área de engenharia; e não trabalha, os que não estão trabalhando. Ao comparar as áreas de atuação, será usado este referencial apresentado. É possível perceber que os egressos da vindos da rede privada estão mais inseridos na área de engenharia em comparação aos da rede pública, 61,69\% em relação a 49,21\%. Por outro lado, os egressos oriundos da rede pública estão mais entre as outras áreas em comparação aos da rede privada, 33,33\% em comparação a $20,78 \%$.

Gráfico 2 - Distribuição dos egressos por área de atuação e rede de ensino de origem.

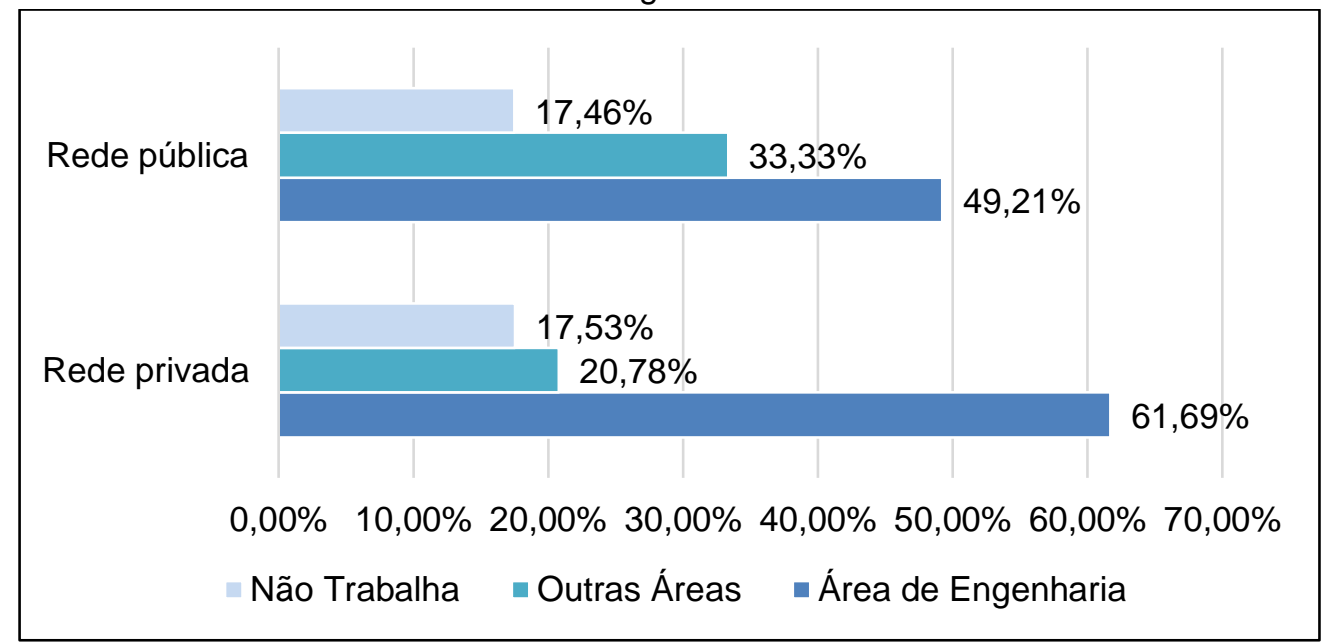

Fonte: Os autores (2021).

\subsection{Formação antes do término da graduação}

A Tabela 3 mostra as formações que os egressos oriundos de cada rede possuíam antes do término da graduação por cada área de atuação. A maioria dos graduados que 
vieram da rede privada e que estão atuando na área de engenharia não possuíam formação antes do término do curso, $43,51 \%$ dos 154 egressos da rede privada ou $70,53 \%$ dos 95 que estão na área. Já os da rede pública, a maioria que está atuando na mesma área possuía curso técnico ao ingressar, isto é, 30,16\% dos 63 egressos desta rede ou $61,29 \%$ dos 31 egressos nesta área.

Tabela 3 - Formação antes do término da graduação por área de atuação por rede de origem

\begin{tabular}{c|c|c|c}
\hline Área de Atuação & Formação Prévia & Rede Privada & Rede Pública \\
\hline \multirow{4}{*}{$\begin{array}{c}\text { Trabalha na Área } \\
\text { de Engenharia }\end{array}$} & Não possuía & $43,51 \%$ & $17,46 \%$ \\
\cline { 2 - 4 } & Graduação em outra área & $12,99 \%$ & $30,16 \%$ \\
\cline { 2 - 4 } & Graduação em outra Engenharia & $1,95 \%$ & $1,59 \%$ \\
\cline { 2 - 4 } & Pós-graduação em outra área & $0,65 \%$ & $0,00 \%$ \\
\hline \multirow{2}{*}{$\begin{array}{c}\text { Trabalha em } \\
\text { Outras Áreas }\end{array}$} & Não possuía & $14,94 \%$ & $0,00 \%$ \\
\cline { 2 - 4 } & Graduação em outra área & $4,55 \%$ & $11,11 \%$ \\
\hline \multirow{2}{*}{ Não Trabalha } & Não possuía & $1,30 \%$ & $3,17 \%$ \\
\cline { 2 - 4 } & Curso técnico & $16,08 \%$ & $9,52 \%$ \\
\hline & Total & $10,65 \%$ & $7,94 \%$ \\
\hline
\end{tabular}

Fonte: Os autores (2021).

Por outro lado, a maioria dos egressos oriundos da rede pública e que estão atuando em outras áreas, assim como na área de engenharia, possuíam curso técnico, 12 dos 21 egressos, isto é, $57,24 \%$. Além disso, é possível visualizar que a maioria dos egressos vindos da rede privada não possuíam formação prévia, 75,33\% dos 154 egressos desta rede.

\subsection{Grau de formação atual}

A Tabela 4 exibe o grau de formação atual dos egressos atuantes de cada área oriundos das redes pública e privada. Ao analisar os egressos que estão atuando na área de engenharia é mais frequente a especialização ou MBA em áreas ligadas à engenharia em relação aos que estão atuando em outras áreas, dos 154 egressos vindos da rede privada, $18,88 \%$ da área de engenharia em comparação aos 3,25\% de outras áreas, enquanto para os 63 egressos que vieram da rede pública a diferença é menor a diferença entre as áreas, $11,11 \%$ da área de engenharia em relação a 6,35\% de outras áreas.

Se for considerado pós-graduações de maneira geral (especialização ou MBA, mestrado ou doutorado, todas na área de engenharia) tem-se que 26,62\% dos 154 oriundos da rede privada, buscaram especializar-se na área de engenharia em comparação aos $4,55 \%$ que estão em outras áreas. O mesmo ocorre para os da rede pública, mas em menores proporções, dos 63 egressos, 17,46\% que estão atuando na área de engenharia especializaram-se em relação a 7,94\% que estão em atuando em outras áreas. 
28 a 30 de SETEMBRO

Tabela 4 - Grau de formação atual por área de atuação das redes pública e privada.

\begin{tabular}{c|c|c|c}
\hline \multirow{2}{*}{ Área de Atuação } & Maior Grau de Formação & $\begin{array}{c}\text { Rede } \\
\text { Privada }\end{array}$ & $\begin{array}{c}\text { Rede } \\
\text { Pública }\end{array}$ \\
\hline \multirow{4}{*}{$\begin{array}{c}\text { Trabalha na Área } \\
\text { de Engenharia }\end{array}$} & Graduação & $34,42 \%$ & $25,40 \%$ \\
\cline { 2 - 4 } & Especialização ou MBA em áreas ligadas à Engenharia & $18,83 \%$ & $11,11 \%$ \\
\cline { 2 - 4 } & Especialização ou MBA em outra área & $0,00 \%$ & $6,35 \%$ \\
\cline { 2 - 4 } & Mestrado na área de Engenharia. & $7,79 \%$ & $6,35 \%$ \\
\hline \multirow{4}{*}{$\begin{array}{c}\text { Trabalha em } \\
\text { Outras Áreas }\end{array}$} & Mestrado em outra área & $0,65 \%$ & $0,00 \%$ \\
\cline { 2 - 4 } & Graduação & $10,39 \%$ & $19,05 \%$ \\
\cline { 2 - 4 } & Especialização ou MBA em áreas ligadas à Engenharia & $3,25 \%$ & $6,35 \%$ \\
\cline { 2 - 4 } & Mespecialização ou MBA em outra área & $5,84 \%$ & $3,17 \%$ \\
\cline { 2 - 4 } & Mestrado em outra área & $1,30 \%$ & $1,59 \%$ \\
\hline \multirow{4}{*}{ Não Trabalha } & Graduação & $0,00 \%$ & $3,17 \%$ \\
\cline { 2 - 4 } & Especialização ou MBA em áreas ligadas à Engenharia & $10,79 \%$ & $12,70 \%$ \\
\cline { 2 - 4 } & Mestrado na área de Engenharia. & $0,00 \%$ & $3,17 \%$ \\
\cline { 2 - 4 } & Mestrado em outra área & $0,67 \%$ & $0,00 \%$ \\
\cline { 2 - 4 } & Doutorado na área de Engenharia & $0,67 \%$ & $0,00 \%$ \\
\hline & Total & $100,00 \%$ & $100,00 \%$ \\
\hline
\end{tabular}

Fonte: Os autores (2021).

\subsection{Tempo de estágio não-obrigatório}

$\mathrm{Na}$ Escola Politécnica de Pernambuco (POLI), os discentes podem exercer o estágio obrigatório a partir de completado $60 \%$ da carga-horária do curso, entretanto, existem casos que os discentes exercem estágio além do obrigatório. A Tabela 5 mostra como está distribuído o tempo de estágio além do obrigatório que os egressos exerceram de cada área de atuação por rede de ensino de origem.

Tabela 5 - Tempo de estágio exercido além do obrigatório de área de atuação por Rede de Ensino de origem

\begin{tabular}{c|c|c|c}
\hline Área de Atuação & Tempo & Rede Privada & Rede Pública \\
\hline \multirow{4}{*}{$\begin{array}{c}\text { Trabalha na Área de } \\
\text { Engenharia }\end{array}$} & Apenas estágio obrigatório & $9,09 \%$ & $7,94 \%$ \\
\cline { 2 - 4 } & Menos de 6 meses de estágio & $2,60 \%$ & $1,59 \%$ \\
\cline { 2 - 4 } & Entre 6 e 12 meses de estágio & $12,99 \%$ & $9,52 \%$ \\
\cline { 2 - 4 } & De 12 a 24 meses de estágio & $21,43 \%$ & $15,87 \%$ \\
\cline { 2 - 4 } & Mais de 24 meses & $15,58 \%$ & $14,29 \%$ \\
\hline \multirow{4}{*}{$\begin{array}{c}\text { Trabalha em Outras } \\
\text { Áreas }\end{array}$} & Apenas estágio obrigatório & $5,84 \%$ & $17,46 \%$ \\
\cline { 2 - 4 } & Menos de 6 meses de estágio & $2,60 \%$ & $3,17 \%$ \\
\cline { 2 - 4 } & Entre 6 e 12 meses de estágio & $7,14 \%$ & $3,17 \%$ \\
\cline { 2 - 4 } & De 12 a 24 meses de estágio & $3,25 \%$ & $4,76 \%$ \\
\cline { 2 - 4 } & Mais de 24 meses & $1,95 \%$ & $4,76 \%$ \\
\hline \multirow{4}{*}{ Não Trabalha } & Apenas estágio obrigatório & $4,55 \%$ & $7,94 \%$ \\
\cline { 2 - 4 } & Menos de 6 meses de estágio & $0,00 \%$ & $0,00 \%$ \\
\cline { 2 - 4 } & Entre 6 e 12 meses de estágio & $3,25 \%$ & $3,17 \%$ \\
\cline { 2 - 4 } & De 12 a 24 meses de estágio & $8,44 \%$ & $3,17 \%$ \\
\cline { 2 - 4 } & Mais de 24 meses & $1,30 \%$ & $100,00 \%$ \\
\hline
\end{tabular}

Fonte: Os autores (2021). 
Os resultados mostram que egressos oriundos da rede privada e pública atuantes na área de engenharia se destacam com relação ao tempo de estágio exercido além do obrigatório sobre os que estão em outras áreas, principalmente no que se refere aos que exerceram por pelo menos 12 meses, 37,01\% dos 154 vindos da rede privada em comparação aos 5,2\% das outras áreas, e 30,16\% dos 63 que vieram da rede pública e atuam na área de engenharia em comparação aos 9,52\% dos que atuam em outras áreas.

Outro ponto destaque é que dos 63 egressos oriundos da rede pública e estão trabalhando em outras áreas que não seja engenharia, grande parte afirmou ter exercido apenas o estágio obrigatório, 11 dos 21 , cerca de $53 \%$.

\subsection{Atividades complementares exercidas durante a graduação}

Segundo González e Ferreira (2010), a transformação do Ensino no ensino superior, a partir da formação integral do profissional do século XXI, pressupõe: o estímulo à atividade investigação-trabalho, conseguindo uma maior integração entre as aulas, o trabalho científico e a prática laboral; e fortalecer a formação de um segundo idioma, inglês ou outro. A Tabela 6 mostra como estão distribuídas as atividades complementares exercidas pelos egressos durante a graduação por área de atuação e por rede de origem.

Tab. 6 - Atividades complementares exercidas durante a graduação por área de atuação por rede de origem

\begin{tabular}{|c|c|c|c|}
\hline Área de Atuação & Atividades & Rede Privada & Rede Pública \\
\hline \multirow{9}{*}{$\begin{array}{c}\text { Trabalha na Área } \\
\text { de Engenharia }\end{array}$} & Eventos Científicos & $29,87 \%$ & $26,98 \%$ \\
\hline & Curso de Idiomas & $24,03 \%$ & $31,75 \%$ \\
\hline & Monitoria & $22,08 \%$ & $19,05 \%$ \\
\hline & Iniciação Científica & $17,53 \%$ & $14,29 \%$ \\
\hline & Programa ou Projeto de Extensão & $10,39 \%$ & $12,70 \%$ \\
\hline & Intercâmbio & $5,19 \%$ & $0,00 \%$ \\
\hline & Empresa Júnior & $3,25 \%$ & $1,59 \%$ \\
\hline & Outro & $0,65 \%$ & $1,59 \%$ \\
\hline & Nenhuma atividade & $14,29 \%$ & $11,11 \%$ \\
\hline \multirow{8}{*}{$\begin{array}{l}\text { Trabalha em } \\
\text { Outras Áreas }\end{array}$} & Eventos Científicos & $8,44 \%$ & $9,52 \%$ \\
\hline & Curso de Idiomas & $11,04 \%$ & $6,35 \%$ \\
\hline & Monitoria & $9,09 \%$ & $3,17 \%$ \\
\hline & Iniciação Científica & $5,19 \%$ & $6,35 \%$ \\
\hline & Programa ou Projeto de Extensão & $5,19 \%$ & $3,17 \%$ \\
\hline & Intercâmbio & $1,30 \%$ & $0,00 \%$ \\
\hline & Empresa Júnior & $1,95 \%$ & $1,59 \%$ \\
\hline & Nenhuma atividade & $3,90 \%$ & $11,11 \%$ \\
\hline \multirow{7}{*}{ Não Trabalha } & Eventos Científicos & $10,79 \%$ & $7,94 \%$ \\
\hline & Curso de Idiomas & $6,74 \%$ & $3,17 \%$ \\
\hline & Monitoria & $8,09 \%$ & $3,17 \%$ \\
\hline & Iniciação Científica & $5,39 \%$ & $4,76 \%$ \\
\hline & Programa ou Projeto de Extensão & $2,70 \%$ & $1,59 \%$ \\
\hline & Intercâmbio & $2,70 \%$ & $1,59 \%$ \\
\hline & Nenhuma atividade & $2,02 \%$ & $6,35 \%$ \\
\hline
\end{tabular}

Fonte: Os autores (2021).

É possível observar na Tabela 6 que eventos científicos, como palestras, congressos e seminários, são as atividades com mais recorrência entre os egressos, 49,10\% para oriundos da rede privada e $44,44 \%$ da pública. Nota-se ainda a busca pela formação em 
outros idiomas, com destaque para os egressos que estão trabalhando na área de engenharia, visto que a porcentagem dos que buscaram é mais que o dobro em comparação aos que trabalham em outras áreas e os desempregados, seja para rede privada $(24,03 \%$ em comparação a $11,04 \%$ e $6,74 \%$, respectivamente), seja para rede pública (31,75\% em comparação a 6,35\% e 3,17\%, respectivamente). Além disso, nota-se a busca pela iniciação científica muito presente nos egressos de ambas as redes, $28,11 \%$ dos 154 da rede privada e $25,40 \%$ dos 63 da rede privada.

\section{CONSIDERAÇÕES FINAIS}

Em meio aos contextos abordados neste artigo, a presente pesquisa avaliativa se torna como importante instrumento de análise da inserção dos egressos no mundo do trabalho, ao analisar os impactos da inserção no mundo do trabalho a partir da participação do egresso como atuante da sua formação, uma vez que busca a abordagem da formação que ele possuía antes de concluir a graduação, as atividades complementares exercidas durante a graduação, tempo de estágios e a formação atual. Além disso, busca observar diferenças dessa inserção a partir de dois perfis de ingressos, os que concluíram o ensino médio na rede de Ensino pública e privada.

Com relação à inserção no mundo do trabalho, a identificação da área de atuação dos egressos permite observar a existência da absorção dos graduados por outras áreas além da formação. Essa absorção pode ser causa pela formação promovida pela POLI, que prepara ele não apenas para o mercado de engenharia, mas permite que possa atuar em várias áreas. Além disso, fica evidente a não existência de outros nichos de atuação da além da engenharia, visto que nenhuma das áreas identificadas chega a 10\%.

Já na questão da formação do egresso antes da conclusão da graduação, os resultados mostram como o curso técnico pode ser um diferencial para a inserção no mundo de trabalho, tanto para a área de engenharia como em outras áreas, principalmente para os egressos oriundos da rede pública que possuem essa formação. Além disso, vale ressaltar que a quantidade de egressos vindos da rede pública possui mais curso técnico que os da rede privada, enquanto a maioria da rede privada não possui nenhuma formação antes do término da graduação.

Com relação ao grau de formação atual do egresso, cerca de $20 \%$ dos egressos que concluíram ensino médio em Rede de Ensino pública e estão trabalhando em outras áreas além da engenharia possuem apenas graduação, que pode ser um impacto da necessidade rápida de inserção no mundo do trabalho, sendo necessária uma investigação mais apurada sobre o motivo deles não terem buscado a especialização. Vale ressaltar ainda que, como visto no início do artigo, isto pode ser um impacto dos constrangimentos sociais, ou como necessidade da inserção rápida no mercado de trabalho.

Para âmbito do estágio além do obrigatório, o tempo que o egresso exerce pode servir como um fator decisivo na hora de ingressar na área de formação, independente da Rede de Ensino de origem. Já para as atividades complementares exercidas durante a graduação, é notório a procura pelos cursos de idiomas, seguindo as tendências do século $\mathrm{XXI}$ de que, como visto anteriormente, é necessário o domínio de pelo menos uma língua estrangeira. Ainda nesse âmbito, é possível perceber que a participação de eventos científicos como palestras e seminários não é um fator decisivo na hora de conseguir um emprego, e uma notoriedade pelo estímulo de Iniciação Científica, que se dá por iniciativas como a "Mostra POLl" que ocorre anualmente e conta com a participação de discentes e trabalhos científicos desenvolvidos por eles. Por fim, não é possível ter uma conclusão relevante sobre a participação dos egressos em projetos e programas de extensão, pois 
essas atividades podem servir para direcionamento da profissão que o aluno pode seguir, sendo um ponto de melhoria para as próximas edições da pesquisa.

\section{Agradecimentos}

Aos egressos dos cursos de engenharia da Escola Politécnica de Pernambuco pela participação voluntária, sugestões de melhorias e contribuições para o desenvolvimento do estudo. Ao NAPSI (Núcleo de Apoio Psicopedagógico Inclusivo), principalmente, à coordenadora Anna Lúcia Miranda e seus integrantes pelo acolhimento da equipe, bem como a gestão da instituição pela dedicação, assistência e fomento ao projeto.

\section{REFERÊNCIAS}

BISSARO, M. N., NUNES, M. A. da C. (2015). Egressos do ensino superior das instituições de ensino privadas de São Mateus, ES: competências necessárias para o mercado de trabalho. Educação Por Escrito, v.6, n.1, p. 134-153, 2015.

BRASIL. Exame Nacional de Cursos - Enade 2005. Resumo Técnico. Brasília, DF: MEC/Inep, 2006.

BRASIL. Ministério da Educação. Conselho Nacional de Educação. Câmara de Educação Superior. Lei № 9.394 de 20 de dezembro de 1996. Lei de Diretrizes e Bases da Educação Nacional. Brasília: Ministério da Educação, 2019. Disponível em: http://portal.mec.gov.br/seesp/arquivos/pdf/lei9394 ldbn1.pdf. Acesso em: 27 abr. 2021.

BRASIL. Ministério da Educação. Conselho Nacional de Educação. Câmara de Educação Superior. Resolução no 2, de 24 de abril de 2019. Institui as Diretrizes Curriculares Nacionais do Curso de Graduação em Engenharia. 2019. Brasília: Ministério da Educação, 2019. Disponível em: https://www.in.gov.br/web/dou/-/resolu\%C3\%87\%C3\%830n\%C2\%BA-2-de-24-de-abril-de-2019-85344528. Acesso em: 27 abr. 2021.

CARVALHO, Pedro Carlos de. Empregabilidade: a competência necessária para o sucesso no novo milênio. 7. ed. Campinas: Alínea, 2011.

FEIJOO, AMLC. Distribuição de frequência. In: A pesquisa e a estatística na psicologia e na educação [online]. Rio de Janeiro: Centro Edelstein de Pesquisas Sociais, p. 6-13, 2010.

FONSECA, João José Saraiva da. Metodologia da pesquisa científica. Curso de Especialização em Comunidades Virtuais de Aprendizagem-Informática Educativa. Universidade Estadual do Ceara, 2002.

FRAGOSO, A.; VALADAS, S. T.; PAULOS, L. Ensino Superior e Empregabilidade: Percepções de Estudantes e Graduados, Empregadores e Acadêmicos. Educação \& Sociedade, Campinas, v.40, e0186612, 2019.

GIL, Antonio Carlos. Como elaborar projetos de pesquisa. 4. ed. São Paulo: Atlas, 2002.

GIL, R. F.; CAMELO, S. H.; LAUS, A. M. Nursing tasks in the Material Storage Center of hospital institutions. Texto contexto - enferm., Florianópolis, v.22, n.4, p.927-934, 2013. 
GONZÁLES, L. M. C.; FERREIRA, A. A. H. Una alternativa metodológica innovadora para formar y evaluar competencias a través de proyectos de curso en las carreras de ingeniería. Revista Educación En Ingeniería, v.5, n.10, p.37-48, 2010.

GUERRA, J. I. M.; HERRERA, M. E. H. Caracterización e impacto de los graduados de la Católica del Norte, Revista Virtual Católica del Norte, v.34, p. 78-112, 2011.

LUIZ, N. M.; COSTA, A. F. da; COSTA, H. G. Influência da Graduação em Engenharia de Produção no Perfil dos seus Egressos: Percepções Discentes. Avaliação (Campinas), Sorocaba, v.15, n.1, p.101-120, 2010.

MAYHEW, K.; KEEP, E. The Assessment of Knowledge, Skills and Competitiveness. Oxford Review of Economic Policy, v. 15, n. 1, p. 1-15, 1999.

ROSA JUNIOR, A. J. Paradigmas Educacionais na Óptica do Mercado de Trabalho. Integração Engenharia, v. 1, 2017.

SILVA, M. R. S. da; OLAVE, M. E. L. Contribuições Das Tecnologias Digitais Associadas à Industria 4.0 para a Formação Profissional. Revista Gestão e Desenvolvimento, Novo Hamburgo, v.17, n.2, p. 82-100, 2020.

SILVEIRA, Olívia. O Unicórnio e o Rinoceronte: uma análise do Projovem a partir da percepção de seus beneficiários. 2009. Dissertação (Mestrado em Educação) Faculdade de Educação, Universidade Federal da Bahia, Salvador, 2009.

TOMLINSON, M. The degree is not enough: students' perceptions of the role of higher education credentials for graduate work and employability. British Journal of Sociology of Education, v. 29, n. 1, 49-61, 2008.

VAZ, Gustavo de Azevedo et al. MERCADO DE TRABALHO, EMPREGABILIDADE E SUAS VARIAÇÕES. 2019.

\title{
THE PARTICIPATION OF THE EGRESS FROM POLI/UPE IN THE INSERTION ON THE WORLD OF WORK: A COMPARATIVE BETWEEN THE EGRESS WHO COMPLETED HIGH SCHOOL IN THE PRIVATE AND PUBLIC NETWORK
}

\begin{abstract}
This article analyzes the participation of the graduate from the Escola Politécnica de Pernambuco (POLI/UPE) as a determining factor for insertion into the world of work based on the activities that they developed during graduation, comparing between two different entry profiles, the ones that completed high school at private and public education network. An online questionnaire was used to fill the graduates of the 7 engineering courses offered by the institution, formed between the periods of 2015.2 and 2019.2, resulting in a total of 902 graduates and 217 responses, which the answers were analyzed by frequency distribution. Most part of the graduates are working in the engineering area (58.06\%), and most of those who come from the public network who are in this area have a technical course (61.29\%), while those from the private network, regardless of the area, do not have previous training (75.33\%). The amount of post-graduates who are working in the engineering area is higher compared to other areas (26.62\% and $17.46 \%$ compared to $4.55 \%$ and $7.94 \%$ of deriving the private and public network respectively). Non-mandatory internships show
\end{abstract}


themselves as a differential for insertion in the world of work, especially considering those who exercised at least 12 months $(37.01 \%$ and $30.16 \%$ of the engineering area compared to $5.2 \%$ and $9.52 \%$ in other areas, for private and public network respectively). There is also a notorious participation in scientific events and scientific initiation during graduation. With this, the research was able to identify that the active participation of the students during the graduation process can be a differential to the insertion in the world of work.

Keywords: Graduates. Influence on training. School of origin. Professional Profile. Quantitative assessment. 